\title{
Esther Gordo*
}

\author{
Andrés Martínez \\ José Miguel Ramos* \\ Lucía Rodríguez*
}

\section{LA DEUDA PÚBLICA EN ESPAÑA: SOSTENIBILIDAD EN UN CONTEXTO DE TIPOS DE INTERÉS REDUCIDOS Y RETOS PARA EL FUTURO MARCO FISCAL}

La deuda pública de la economía española ha alcanzado niveles no vistos anteriormente en tiempos de paz. La persistencia de unas condiciones de financiación extraordinariamente favorables no será suficiente para reconducir la deuda hacia niveles que nos hagan menos vulnerables. Será necesario diseñar una estrategia de consolidación enmarcada en un marco de supervisión fiscal europeo más robusto, que tenga en cuenta tanto la heterogeneidad en los niveles de deuda de las economías europeas como los cambios en las condiciones macroeconómicas de los años recientes.

\section{Public debt in Spain: sustainability in a context of low interest rates and challenges for the future fiscal framework}

Public debt of the Spanish economy has reached levels not previously seen in peacetime. The persistence of extraordinarily favorable financing conditions will not be enough to redirect debt to levels that make us less vulnerable. It will be necessary to design a consolidation strategy framed within a more robust European fiscal framework, which takes into account both the heterogeneity in debt levels of the European economies and the changes in macroeconomic conditions in recent years.

Palabras clave: deuda pública, sostenibilidad, marco de supervisión fiscal.

Keywords: government debt, sustainability, European fiscal framework.

JEL: E6.

\footnotetext{
* Autoridad Independiente de Responsabilidad Fiscal (AIReF).

Contacto: esther.gordo@airef.es; andres.martinez@airef.es; josemiguel.ramos@airef.es; lucia.rodriguez@airef.es

Versión de noviembre de 2021.

https://doi.org/10.32796/ice.2021.923.7335
} 


\section{Introducción}

El nivel de la deuda pública en la economía española ha alcanzado registros no vistos anteriormente en tiempos de paz. En tan solo dos décadas hemos asistido a dos crisis extremas, primero la crisis financiera y, después, la crisis sanitaria, que han dejado una cicatriz profunda en los niveles de deuda pública de las economías avanzadas desde 2009, que ya venían mostrando una trayectoria ascendente en las décadas recientes. En la zona euro se estima que la deuda pública alcanzará un $102 \%$ del PIB en 2021, frente al $66 \%$ observado en 2007. Dentro de esta zona la economía española ha registrado uno de los mayores incrementos de los niveles de deuda (solo por detrás de Grecia), de modo que en pocos años ha pasado de ser una de las economías con menores niveles de deuda de la Unión Económica y Monetaria (UEM), un $36 \%$ en 2007, a uno de los países con niveles más altos. Este cambio de régimen tiene implicaciones de alcance en el funcionamiento de la economía y constituirá un condicionante de política económica en los próximos años.

El incremento de deuda pública en España y en otras economías avanzadas ha venido acompañado de profundos cambios en el comportamiento subyacente de la economía. Las tendencias demográficas, los bajos crecimientos de la productividad o el exceso de ahorro de algunas economías configuraron una «nueva normalidad» en el periodo anterior a la pandemia, caracterizado por la persistencia de ritmos de crecimiento reducidos, una baja inflación y una trayectoria descendente de los tipos de interés reales de equilibrio hasta alcanzar mínimos históricos. Esta senda se ha trasladado a los tipos de mercado, que han llegado a situarse en valores negativos en muchas economías. Así, el diferencial entre los tipos de interés y el crecimiento económico que, junto con el saldo primario, determina de manera esencial la evolución de la deuda, ha tornado negativo. Ello ha llevado a cuestionar si los parámetros con los que tradicionalmente se evaluaba la sostenibilidad de la deuda siguen siendo válidos en este nuevo contexto. Un entorno que, dado el carácter secular de sus determinantes, cabe prever que prevalezca tras la pandemia de la COVID-19, toda vez que se disipen los problemas de oferta y las presiones inflacionistas observadas en la salida de la crisis. ¿Cuáles son las implicaciones de los altos niveles de deuda en este contexto? ¿Aumentan los niveles de deuda sostenibles para una economía?

Este artículo se estructura como sigue: en primer lugar, se describen los principales rasgos de la evolución de la deuda española y se presentan proyecciones de la deuda a medio y largo plazo para ofrecer una perspectiva más completa de la magnitud del desafío a que nos enfrentamos. En segundo lugar, se resume la literatura empírica existente sobre el impacto de la deuda en el crecimiento económico, los factores que determinan los niveles prudentes de deuda y se discute cómo estos se pueden ver condicionados por el contexto macroeconómico actual. Finalmente, se discuten las implicaciones que se derivan de los altos niveles de deuda para el diseño de un nuevo marco de supervisión fiscal europeo que regirá una vez se supere la crisis sanitaria y en el que deberá abordarse el futuro proceso de consolidación de la deuda.

\section{La evolución de la deuda y los factores que condicionan su sostenibilidad}

La caída de la actividad económica provocada por la COVID-19 y el despliegue de las medidas necesarias para sostener las rentas de los hogares y de las empresas han tenido un fuerte impacto en las cuentas públicas, elevando los niveles de deuda hasta valores máximos en tiempos de paz. España se encuentra entre las economías con niveles de deuda en un rango elevado, entre 100 y $150 \%$ del PIB, junto con Bélgica, Portugal, Francia, Reino Unido y Estados Unidos. Por su parte, Japón y Grecia presentan niveles de deuda pública que superan en dos veces el tamaño de su PIB, seguidos de Italia, donde la deuda pública representa un $150 \%$ del PIB (Figura 1).

Los altos niveles de endeudamiento reflejan el impacto de las dos perturbaciones extremas vividas en tan solo 


\section{FIGURA 1}

\section{EVOLUCIÓN DE LA DEUDA PÚBLICA}
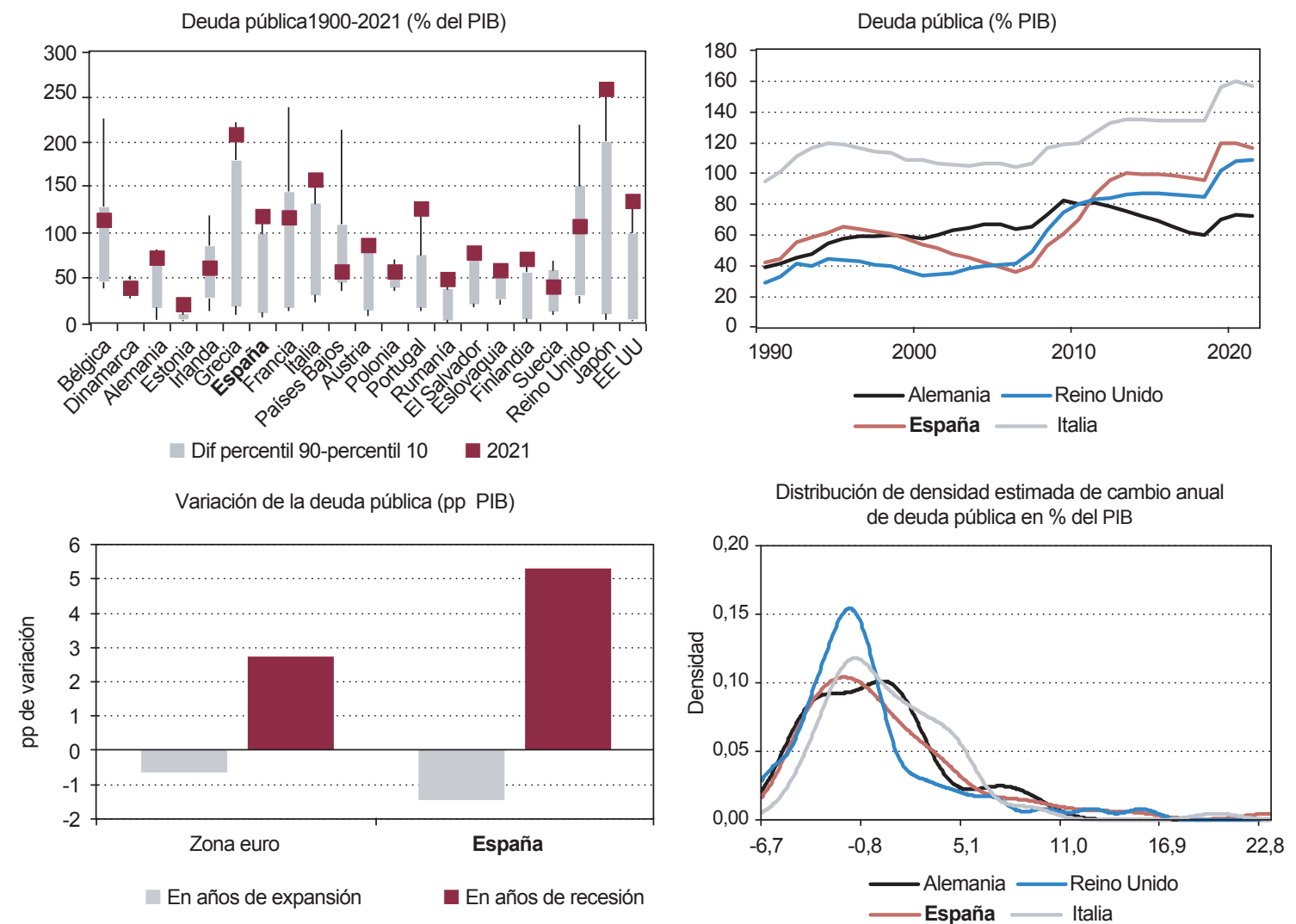

FUENTE: IMF Historical Public Debt Database y AMECO.

14 años: primero, la crisis financiera internacional que supuso un incremento de la deuda próximo a 30 puntos porcentuales (en adelante pp) en el promedio de las economías avanzadas y de $65 \mathrm{pp}$ del PIB en el caso de España; posteriormente, la COVID-19 ha supuesto un aumento próximo a $15 \mathrm{pp}$ en las economías avanzadas y de 27 pp en el caso de España ${ }^{1}$. Cuando se mira con perspectiva histórica, la distribución del cambio anual de

\footnotetext{
${ }^{1}$ El fuerte incremento registrado en España se debe tanto a la elevada volatilidad del PIB, en comparación con otras economías similares, como a la activación de estabilizadores automáticos y medidas fiscales extraordinarias necesarias para mitigar el impacto de la crisis sobre el tejido productivo y sobre la sociedad.
}

la deuda de las economías avanzadas revela una larga cola a la derecha que advierte que, así como algunas perturbaciones extremas han provocado incrementos intensos de la deuda, no cabe esperar perturbaciones de signo contrario que compensen estos movimientos.

El impacto de estas perturbaciones asimétricas se añade a una trayectoria ascendente subyacente en la mayoría de las economías avanzadas. Los periodos de contención de la deuda han sido, en general, escasos y breves. Los notables incrementos de la deuda que se observan en los periodos de recesión vienen acompañados de cierta histéresis o resistencia a la baja en los periodos de expansión. 
En España estos movimientos son incluso más intensos que los observados en el promedio de la UEM. De hecho, en dos décadas España ha transitado desde una economía con niveles reducidos de deuda hacia el conjunto de economías avanzadas con mayores niveles de deuda. En concreto, tras alcanzar un máximo de $66 \%$ del PIB en 1996, el esfuerzo de convergencia realizado para la entrada en la UEM y la fuerte expansión cíclica de comienzos de los años 2000 supuso que la deuda se redujera hasta un mínimo del $35,5 \%$ del PIB en 2007. Posteriormente, en tan solo 14 años, la deuda ha aumentado más de $90 \mathrm{pp}$ del PIB, hasta niveles máximos del $125 \%$ del PIB en 2021, que sitúan a esta variable en el centro del debate económico (Figura 2).

A corto y medio plazo, cabe esperar una reducción de la ratio de deuda en un contexto de recuperación económica. En particular, de acuerdo con las previsiones macrofiscales elaboradas por AIReF, el rebote esperado de la actividad económica impulsada por el Plan Europeo de Recuperación, Transformación y Resiliencia (PRTR), la mejoría del componente cíclico del saldo público y la paulatina desaparición de las medidas de emergencia relacionadas con la pandemia, permiten proyectar una reducción de la ratio de deuda de entre 3 y 7 puntos para el año $2024^{2}$.

A partir de ese momento, las proyecciones de AIReF apuntan a una dinámica de la ratio de deuda levemente creciente si el déficit primario estructural

\footnotetext{
2 En línea con algunos organismos internacionales, la AIReF realiza periódicamente un análisis de sostenibilidad de la deuda que publica en su Observatorio de Deuda AIReF | Data Lab. Observatorio Interactivo de Deuda Pública. Este análisis de sostenibilidad se basa en la elaboración de proyecciones para la deuda pública que se obtienen mediante aproximaciones metodológicas complementarias (de naturaleza estocástica y determinista) y supuestos alternativos acerca de la evolución futura de los determinantes fundamentales de la deuda (el PIB, los tipos de interés, los saldos primarios y la inflación). Estos análisis permiten incorporar también el impacto de los pasivos contingentes asociados al envejecimiento de la población o a las ayudas públicas a empresas. En European Union Independent Fiscal Institutions (2021) puede encontrarse una revisión de las técnicas empleadas por las principales instituciones independientes existentes en Europa para el análisis de sostenibilidad de la deuda.
}

se mantuviera en el nivel previsto para 2024 —del $2,5 \%$ del PIB - y asumiendo un crecimiento nominal promedio del 3,3\% $\%^{3}$ y unos tipos de emisión de la deuda que situarían su tipo implícito en valores incluso inferiores al mínimo registrado en 2020. Bajo estos supuestos, la contribución positiva a la reducción de la ratio de deuda del diferencial del tipo de interés sobre el crecimiento (58 puntos acumulados en 2050) no sería suficiente para compensar el déficit primario estructural (80 puntos acumulados en 2050).

A esto hay que sumar la presión al alza sobre la deuda que ejercerá el envejecimiento poblacional en los próximos años. En particular, el gasto en pensiones asociado a la transición demográfica podría incrementar en $54 \mathrm{pp}$ la ratio de deuda en los próximos 30 años si no se adoptan medidas para compensarlo, lo que nos situaría con niveles de deuda próximos al $190 \%$ del PIB (63 puntos de contribución positiva del diferencial del tipo de interés sobre el crecimiento serán insuficientes para compensar los 134 puntos de déficit primario estructural acumulados en 2050), cercanos a los que registra Grecia en la actualidad.

En este contexto resulta relevante debatir qué implicaciones se derivan de estos niveles de deuda y hacia qué nivel debería converger de acuerdo con la literatura empírica.

\footnotetext{
${ }^{3}$ El escenario macroeconómico se basa en un enfoque integrador de building blocks que permite determinar el PIB de la economía. Así, el PIB se determina mediante una función de producción, en la que el output total se determina como una combinación del factor trabajo $(\mathrm{L})$ y productividad aparente del trabajo (PAT), que incluye el efecto del capital y el progreso técnico. Un mayor detalle técnico se puede consultar en el Documento de Trabajo: Modelo AIReF de proyección del gasto en pensiones en España. En la aproximación al crecimiento a largo plazo no se han considerado los posibles efectos del PRTR en el aumento de la productividad (por la vía de mayor inversión en capital público y la adopción de reformas que incrementen el desempeño potencial de la economía en el futuro, cuyo contenido se desconoce todavía). Las simulaciones realizadas por AIReF en el Observatorio de Deuda de noviembre muestran que un mayor crecimiento potencial a medio y largo plazo (1 pp) puede llegar a suponer una disminución de la ratio de deuda en el largo plazo en torno a 20 pp ante un mismo esfuerzo de consolidación fiscal.
} 
FIGURA 2

PROYECCIÓN DE LA RATIO DE DEUDA Y FACTORES DETERMINANTES

(En \% PIB)
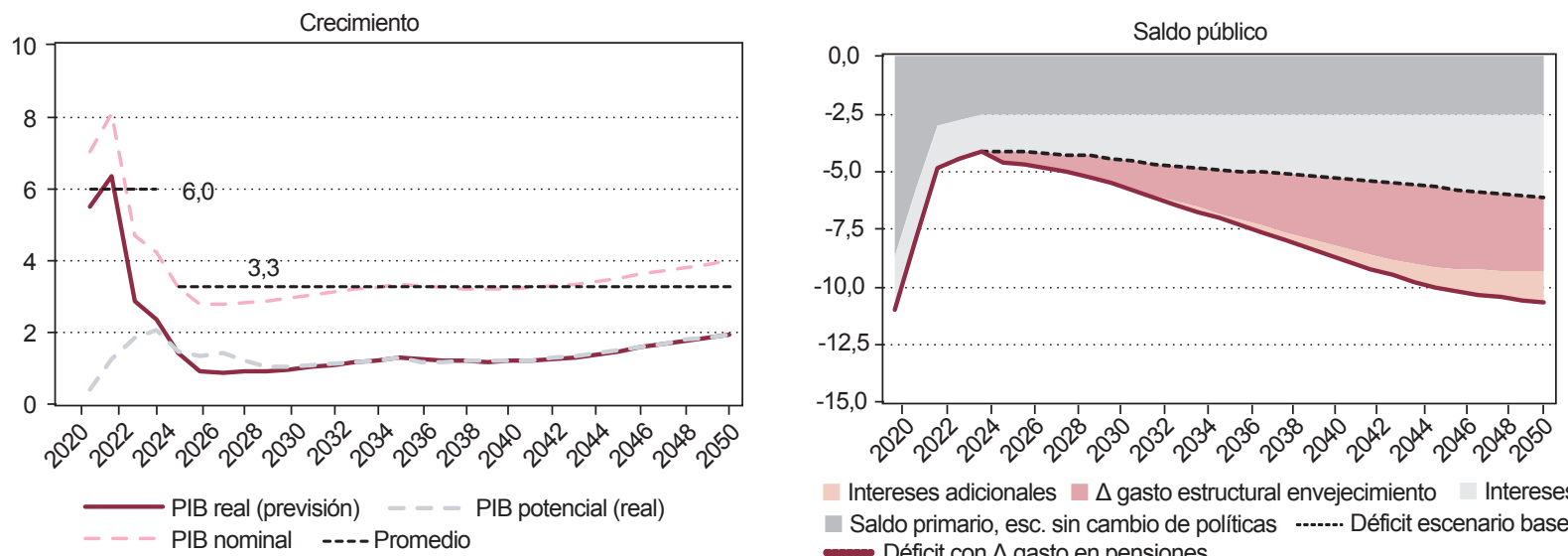

$\square$ Intereses adicionales $\square$ gasto estructural envejecimiento Intereses Saldo primario, esc. sin cambio de políticas ....... Déficit escenario base Déficit con $\Delta$ gasto en pensiones

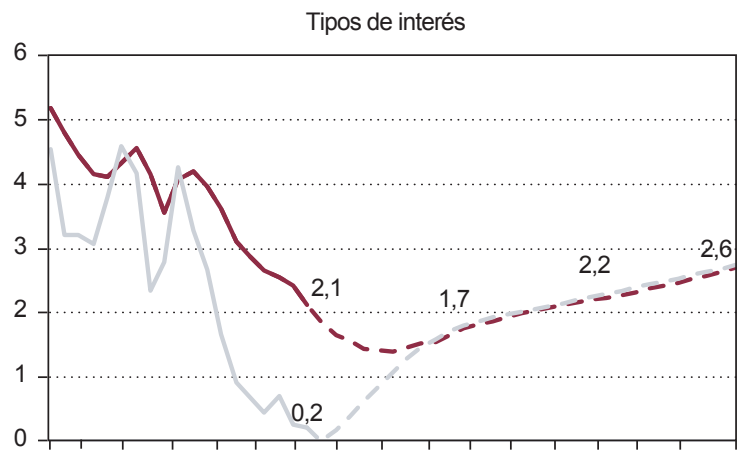

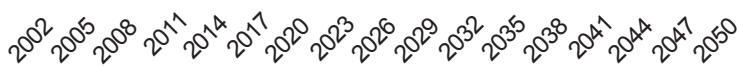
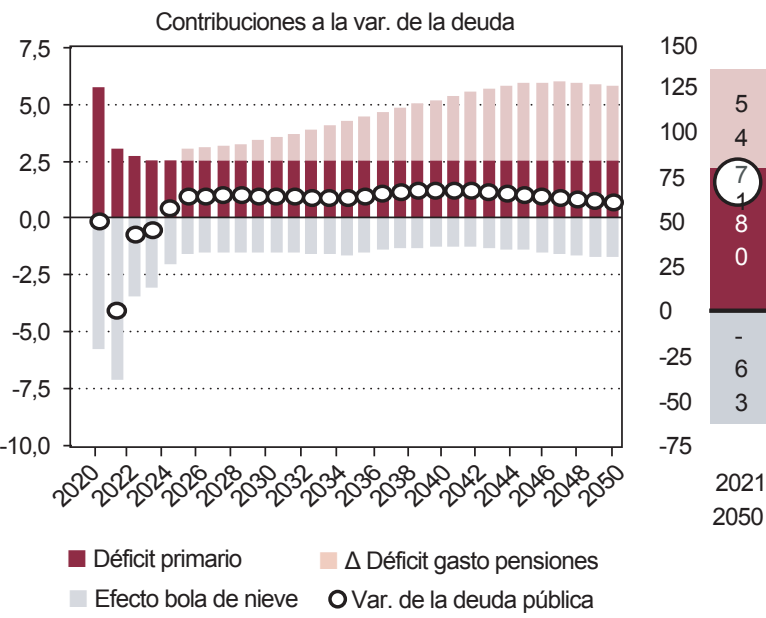

- - - Tipo de interés implícito $\quad--$ Nuevas emisiones

Proyección de deuda
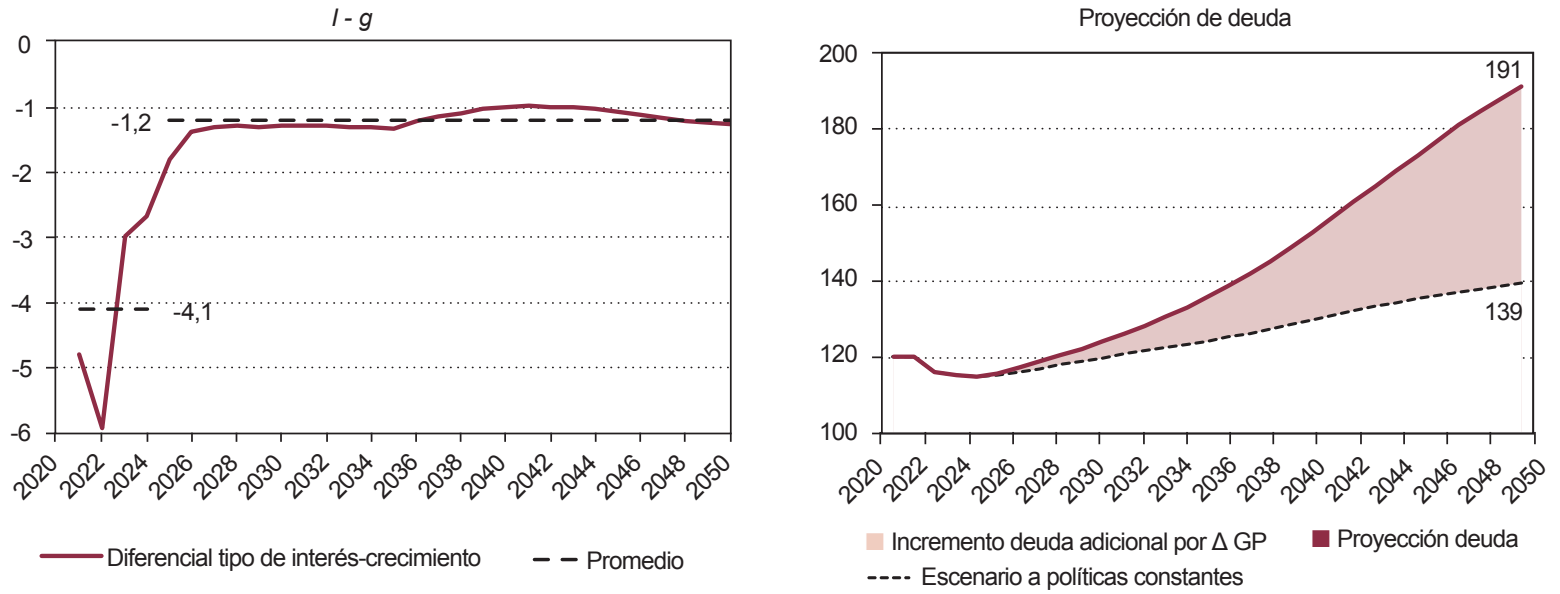

FUENTE: Elaboración propia. 
3. Reflexiones sobre los niveles de deuda pública: la sostenibilidad en un entorno de bajos tipos de interés

La existencia de deuda es inherente al funcionamiento de las economías de mercado ${ }^{4}$. El endeudamiento juega un papel esencial para suavizar el impacto de perturbaciones como las vividas en los años recientes y permite afrontar necesidades de inversión excepcionalmente grandes, como proyectos de infraestructuras o el cambio climático, que tienen implicaciones favorables a lo largo del tiempo (Eichengreen et al., 2021). La deuda juega, además, un papel vital en el sistema financiero al constituir un activo líquido y relativamente seguro para los ahorradores, al tiempo que se emplea como colateral en las operaciones y programas de compras de activos de los bancos centrales, contribuyendo así a la transmisión de las decisiones de política monetaria. Pero una acumulación excesiva de deuda no está exenta de riesgos.

\section{La relación entre los niveles de deuda y el crecimiento económico}

En particular, frente a los postulados de la teoría monetaria moderna, que argumenta que la deuda pública puede crecer indefinidamente siempre que el banco central pueda imprimir dinero para financiarla (Douglas \& Raudla, 2020), el consenso señala que por encima de determinados niveles la deuda puede tener efectos negativos para el crecimiento.

Estos efectos pueden discurrir a través de múltiples canales. Por un lado, un alto endeudamiento provoca que la economía sea más vulnerable a shocks macroeconómicos, al limitar el espacio fiscal para llevar a cabo

\footnotetext{
${ }^{4}$ Aunque esto parece evidente, no es menos cierto que existen connotaciones negativas asociadas a la acumulación de deuda que históricamente han impregnado el lenguaje. Así, por ejemplo, el vocablo alemán para deuda (schuldt) significa también culpabilidad o falta. En el idioma inglés, la palabra utilizada para amortizar deuda (redeem) significa también redimir los pecados.
}

políticas económicas contracíclicas. Hay evidencia que sugiere que, dentro de la UEM, los países que tenían mayores niveles de deuda han respondido en menor medida a la crisis sanitaria (Romer, 2021) y, con carácter más general, existe un conjunto de literatura que muestra cómo los gobiernos de países con menores niveles de deuda tienden a ofrecer una respuesta de política fiscal más adecuada y oportuna (Fatás \& Mihov, 2012).

Además, una economía con alto endeudamiento requiere de una continua refinanciación de la deuda. Ante un shock macroeconómico, el mercado puede mostrar dudas sobre su capacidad de repago, dudas que pueden reflejarse en una mayor prima de riesgo y costes de financiación. Este riesgo podría ser mayor para los países de una unión monetaria que no disponen de un banco central propio, dado que ceden el control de la divisa en la que emiten sus obligaciones (De Grauwe, 2012). Especialmente, en el caso de la UEM, existe el riesgo de que se desencadenen círculos viciosos de riesgo soberano y riesgo bancario a través del canal de balance (Véron, 2012), sin perjuicio de que las reformas regulatorias tras la crisis financiera hayan tratado de debilitar los elementos de retroalimentación entre el soberano y el sistema financiero, modificando el tratamiento de los activos de deuda pública en la regulación financiera.

Finalmente, si la deuda pública se emite para financiar gasto improductivo o niveles subóptimos de capital público, el crecimiento económico en el largo plazo se puede resentir. El sector público estaría detrayendo fondos para emplearlos en proyectos cuya productividad sería inferior a la que podría tener el sector privado (crowding-out) debiendo afrontar en un futuro incrementos de impuestos distorsionadores para financiar la deuda 5 .

\footnotetext{
${ }^{5}$ Estos canales han sido estudiados a través de modelos de equilibrio general. Por ejemplo, Burriel et al. (2020) simulan los efectos de un shock económico adverso en economías con alto endeudamiento en tres modelos multipaís diferentes. Además de los elementos mencionados, ponen de relieve un efecto de «segunda ronda» teórico por la restricción presupuestaria intertemporal del Gobierno. Un shock negativo a un país altamente endeudado conduce a un mayor riesgo soberano y costes
} 
Sin embargo, pese a la multitud de canales teóricos, en general, la evidencia empírica sobre la relación entre los niveles de deuda pública y el crecimiento no es concluyente. Una de las contribuciones más influyentes en esta literatura es el trabajo de Reinhart y Rogoff (2010), no tanto por sus controvertidos resultados, sino porque desencadenó un interés creciente en contrastar esta relación de forma empírica. En ese trabajo se estima un umbral para la deuda próximo al $90 \%$ del PIB, por encima del cual se pueden identificar efectos negativos de un alto endeudamiento sobre el crecimiento económico.

Así, surge un conjunto de trabajos entre los que se encuentran Cechetti et al. (2011), Checherita-Westphal y Rother (2012) o Kumar y Woo (2010), que sugieren que existe una relación de causalidad entre los elevados niveles de deuda pública existentes en algunas economías y su menor crecimiento económico. Para el caso concreto de la zona euro, Checherita-Westphal y Rother (2012) señalan que los elevados niveles de endeudamiento tienen efectos negativos sobre el ahorro privado y están asociados a una menor productividad en línea con la utilización de recursos para financiar gasto improductivo. En el caso de España, Esteve y Tamarit (2018) encuentran que un incremento de $10 \mathrm{pp}$ en la ratio deuda pública-PIB estaría asociado a una reducción del crecimiento anual del PIB real de entre 0,17 pp y $0,26 \mathrm{pp}$.

La mayoría de estos trabajos subrayan la «no linealidad» de los efectos negativos del alto endeudamiento $y$, en concreto, tienden a confirmar un umbral del $90 \%$, por debajo del cual no parece existir la relación negativa entre deuda y crecimiento $^{6}$, e incluso algunos

de financiación. El Gobierno debe contrarrestar este incremento de intereses, y por tanto de gasto público, con mayores ingresos a través de impuestos distorsionadores de la actividad, lo que redunda en una reducción adicional del $\mathrm{PIB}$ y, por tanto, un incremento aún mayor de la ratio deuda pública y $\mathrm{PIB}$.

${ }^{6}$ Cecchetti et al. (2011) encuentran un umbral del $86 \%$ del PIB para un panel de 18 países de la OCDE y para el periodo de 1980 a 2010.

Por su parte, Kumar y Woo (2010) sitúan ese umbral por encima del 90

$\%$ del PIB para un amplio conjunto de países avanzados y emergentes.

En el caso de la zona euro, Checherita-Westphal y Rother (2012) autores encuentran una relación positiva (Baum et al., 2013).

En cambio, otro conjunto de trabajos (Panizza \& Presbitero, 2013; Égert, 2015) encuentran que la presencia y el nivel de los umbrales de deuda estimados en la literatura previa son poco robustos a pequeños cambios en la cobertura de los países y el periodo temporal analizado. Incluso en algunas ocasiones se encuentra una relación de causalidad inversa. Si bien los países con alta deuda pública tienden a crecer más lentamente, transformar esta correlación en una relación causal unidireccional e impermeable a otros factores es probablemente un afán quimérico de la actividad investigadora.

\section{¿Qué factores determinan los niveles de deuda prudentes para una economía?}

Existen argumentos para pensar que la sostenibilidad de la deuda pública depende de la idiosincrasia económica de cada país. Así, coexisten países como Japón, que ha sido capaz de mantener niveles de deuda próximos al $200 \%$ del PIB durante muchos años, con otros como Ucrania, que tuvo que afrontar una reestructuración de su deuda cuando esta no superaba el $40 \%$ de su PIB.

Por ello, otra corriente de la literatura se centra en determinar cuáles son las características que permiten que unos países sostengan determinados niveles de deuda sin desencadenar reacciones adversas de las primas de riesgo en los mercados de deuda soberana ${ }^{7}$.

sugieren una relación en forma de $\mathrm{U}$ invertida entre la deuda pública y el crecimiento; cuando la deuda es reducida, un incremento de la deuda suele llevar aparejado un mayor crecimiento; pero por encima del umbral del $90-100 \%$ del PIB, la deuda pública tiene efectos negativos sobre el PIB de las economías europeas. Otros autores encuentran umbrales inferiores. Así, Caner et al. (2010) muestran que el punto de inflexión es probablemente menor: $77 \%$ para un conjunto de países de la OCDE y del $66 \%$ para las economías emergentes.

7 Esta literatura se centra en determinar si existen «límites de deuda» que los países no deberían superar para no desencadenar reacciones adversas en los mercados o porque la superación de esos niveles requeriría alcanzar superávits primarios para sostener o reconducir los niveles de deuda, que son poco probables por razones políticas o 
La calidad institucional y democrática y la estabilidad política se encuentran entre los factores a los que esta literatura apunta de manera unánime (Ghosh et al., 2013). También el grado de apertura externa de la economía incide de manera positiva sobre los niveles de deuda «prudentes» al permitir acceder a una base inversora mayor y más diversificada a través de los mercados de capital foráneos. En cambio, una estructura productiva muy concentrada que proyecte volatilidad sobre el crecimiento económico incide de manera negativa sobre los niveles de deuda «prudentes». El envejecimiento demográfico tiene efectos ambiguos, ya que, por un lado, se refleja en un menor crecimiento potencial -a través de una menor tasa de participación y menor crecimiento de la productividad (European Commission, 2021) —, pero también viene acompañado de mayores tasas de ahorro y menores tipos de interés de equilibrio.

Por otro lado, la literatura señala que los países que emiten una moneda que tiene el carácter de reserva, como el dólar, se enfrentan a menores riesgos de liquidez $\mathrm{y}$, por tanto, pueden afrontar mayores niveles de deuda. En cambio, la experiencia de la crisis de la deuda soberana europea muestra cómo los países pertenecientes a una unión monetaria, que no cuentan con un banco central propio, se encuentran más expuestos a reacciones adversas en los mercados de deuda en caso de crisis severas (De Grauwe, 2012).

Finalmente, también influyen otras características relativas a la composición de la deuda y a su estructura de vencimientos. Por ejemplo, una cartera de deuda compuesta por instrumentos de corto plazo eleva la vulnerabilidad de una economía, dado que sus necesidades de refinanciación son más inmediatas que una economía cuya cartera tenga una vida media más

económicas. Entre los trabajos más relevantes de esta literatura destacan Ghosh et al. (2013), que estiman límites de deuda muy elevados para la mayoría de los países, próximos al $200 \%$, que justifican por la prevalencia de tipos de interés muy reducidos, inferiores al crecimiento económico. Para España, Alloza et al (2020) tratan de caracterizar empíricamente el límite prudente de deuda publica coherente con las expectativas de los mercados financieros y sitúa ese umbral en torno al $60 \%$ del PIB elevada. Asimismo, la proporción de deuda en manos de extranjeros proporciona el acceso a una base de inversores más diversificada, lo que puede reducir los costes de financiación, pero también se puede tornar una fuente de vulnerabilidad en caso de perturbaciones, ya que los inversores extranjeros suelen presentar mayor volatilidad. En el caso de Japón, por ejemplo, se argumenta que sus elevados niveles de deuda se encuentran estrechamente ligados a la proporción elevada de deuda en manos de residentes en un contexto de elevadas tasas de ahorro (Hoshi \& Ito, 2014).

\section{La importancia del contexto macroeconómico para la sostenibilidad de la deuda}

Por último, el nivel de deuda sostenible a medio plazo depende de los fundamentales macroeconómicos de cada país. En el largo plazo, el saldo primario que permite estabilizar el nivel de deuda depende del diferencial entre el tipo de interés real y la tasa de crecimiento real del producto. Cuanto menor sea la brecha entre los tipos de interés y el crecimiento, menor será el saldo primario necesario para estabilizar los niveles de deuda a medio plazo.

En este sentido, con anterioridad a la crisis sanitaria provocada por la COVID-19, el consenso emergente señalaba cambios fundamentales en el modelo de crecimiento global que justificaban la persistencia de tipos de interés estructuralmente reducidos o incluso negativos. En particular, Rachel y Summers (2019) enfatizan algunos factores estructurales, como el envejecimiento de la población, el ahorro estructuralmente alto, la baja inversión y la disminución de la productividad a nivel global, que han provocado una reducción del crecimiento a largo plazo (estancamiento secular) y una disminución permanente de la tasa de interés real de equilibrio (o tasa natural), hasta valores históricamente reducidos. Paralelamente, los tipos de interés de mercado se han situado en niveles próximos a cero o incluso negativos, lo que ha determinado que el diferencial entre los tipos de interés y el crecimiento sea negativo. 
En este contexto, influyentes autores como Blanchard y Summers (2019) reclaman una reconsideración del papel que pueden desempeñar la política fiscal y la deuda para estabilizar la economía y ofrecer una respuesta adecuada a esta «nueva normalidad» (Blanchard, 2019). Por un lado, dado que los tipos de interés se encuentran próximos a su límite inferior efectivo, una expansión fiscal no provocará la reacción de la política monetaria de subida de tipos, de modo que sus efectos multiplicadores serán mayores, al no existir crowding-out sobre la inversión privada ${ }^{8}$. El estímulo fiscal resultará todavía más eficaz cuando se adopta de manera coordinada internacionalmente (Christiano et al., 2011; Furman, 2016).

Además, la persistencia de bajos costes de financiación soberana - pese a los incrementos recientes de deuda pública y a las políticas fiscales expansivas aplicadas en diversos países- parece indicar que los potenciales costes asociados a los niveles de deuda pública pueden ser menores de lo que eran en el pasado (Blanchard \& Ubide, 2019). Especialmente si el aumento del gasto público se destina a financiar inversión pública de calidad, la lucha contra el cambio climático o gasto en innovación con un fuerte impacto sobre el crecimiento a largo plazo ${ }^{9}$. No obstante, no se puede olvidar el papel crucial que ha desempeñado la política monetaria a la hora de mantener esas condiciones de financiación tan favorables.

\footnotetext{
${ }^{8}$ En este contexto se ha fraguado un consenso en torno a la idea de que es necesario repensar la interrelación entre política monetaria y política fiscal. Así se refleja, por ejemplo, en el $23 .^{\circ}$ Informe de Ginebra sobre la Economía Mundial del año 2020, que recoge cómo la discusión sobre la coordinación de políticas monetarias y fiscales, que surgió en el entorno de bajo crecimiento y baja inflación observado en las últimas décadas, ha resurgido de forma espectacular cuando los países se han visto obligados a asumir las devastadoras consecuencias económicas de la pandemia de la COVID-19. El informe subraya que la deseable coordinación entre los bancos centrales y las autoridades fiscales solo puede funcionar si la credibilidad de su compromiso con los objetivos de largo plazo — crecimiento sólido bajo estabilidad de precios y sostenibilidad de la deuda pública- se preserva y está respaldada por un marco institucional robusto.

${ }^{9}$ Algunos autores argumentan que una política fiscal expansiva que incremente el crecimiento potencial podría autofinanciarse si los tipos de interés permanecen estables y moderados (DeLong \& Summers, 2012).
}

En consecuencia, los niveles de deuda que una economía puede sostener sin que surjan inestabilidades en los mercados de deuda dependen de multitud de factores y pueden ser cambiantes en el tiempo, de modo que en la actualidad es posible que las economías avanzadas puedan sostener niveles mayores que en el pasado. Pero, para ello, resulta clave la existencia de un diferencial negativo entre los tipos de interés y el crecimiento (Mehrotra \& Sergeyev, 2021).

En ese sentido, la literatura que se ha centrado en analizar el diferencial entre los tipos de interés y crecimiento $(r-g)$ arroja algunas cautelas. En particular, pese a que los determinantes de los reducidos niveles de interés existentes en la actualidad son de naturaleza estructural, el diferencial entre los tipos de interés y el crecimiento ha fluctuado mucho en el pasado y no hay garantía de que $r-g$ siga siendo negativo en un futuro, aunque históricamente haya sido una característica frecuente (Checherita-Westphal \& Domingues, 2020). En otros trabajos se argumenta que el hecho de que existan diferenciales negativos entre los tipos de interés y el crecimiento no es indicativo de una mayor sostenibilidad, ya que en el pasado algunas economías registraron diferenciales negativos inmediatamente antes de tener que abordar un proceso de reestructuración de su deuda tras perder el acceso a los mercados financieros (Mauro \& Zhou, 2020). De hecho, $r$-g puede ser endógeno al nivel y la dinámica de la deuda pública (Wyplosz, 2019; Lian et al., 2020)10. Si los inversores creen que la deuda está sujeta a riesgos de sostenibilidad, requerirían una prima de riesgo más alta que aumentaría los costes fiscales de la deuda y haría que la deuda sea efectivamente más costosa.

\footnotetext{
${ }_{10}$ Lian et al. (2020), utilizando una muestra amplia de economías avanzadas y emergentes, encuentran que los niveles elevados de deuda pública pueden conducir a una dinámica futura adversa de $r$ - $g$. Específicamente, se encuentra que los países con mayor deuda pública inicial experimentan: i) una menor frecuencia de episodios donde se aprecia que $r$-g es negativo; además, estos episodios son más cortos y tienen una mayor probabilidad de reversión; y ii) un promedio más alto de $r$ - $g$ y mayores riesgos de que estos se incrementen, particularmente cuando existe una elevada proporción de deuda denominada en moneda extranjera.
} 
FIGURA 3

DIFERENCIAL TIPOS DE INTERÉS A LARGO PLAZO Y CRECIMIENTO REAL
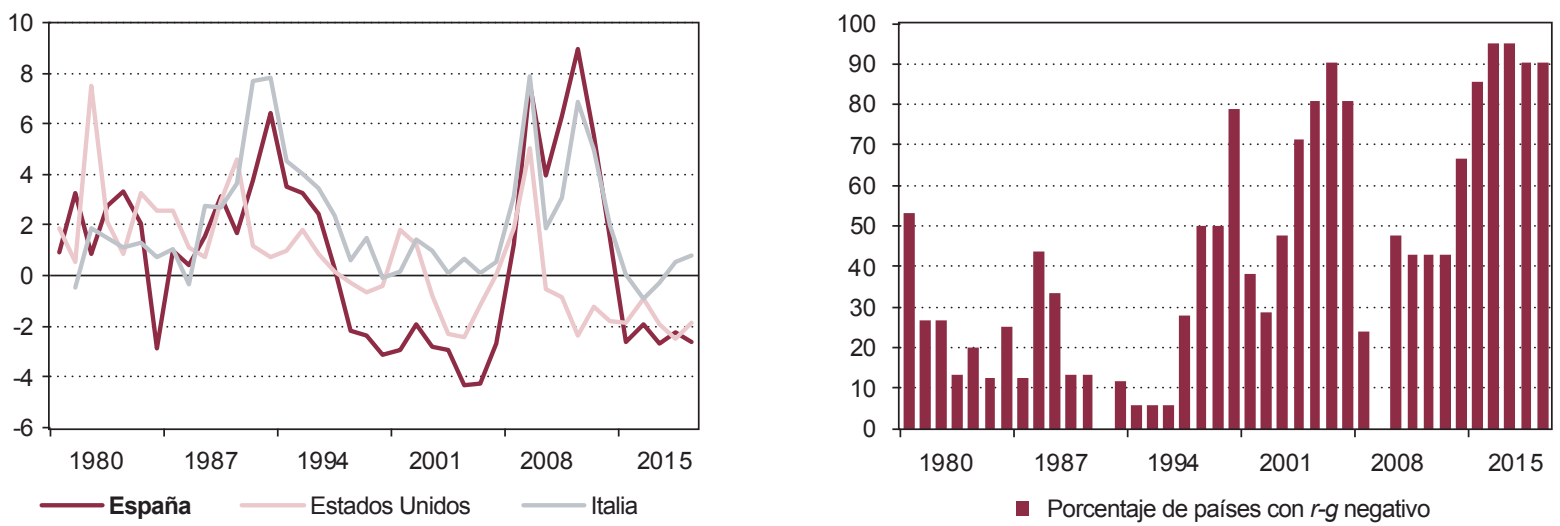

FUENTE: Elaboración propia.

Además, se aprecian grandes diferencias por países. Como se ve en la Figura 3, en Estados Unidos el diferencial ha sido negativo en la mayoría de los años transcurridos desde 1980. En cambio, en Italia ha sido persistentemente positivo debido al bajo crecimiento de la economía. En España, se han alternado periodos con diferenciales positivos y negativos - fue negativo durante el prolongado periodo de expansión observado desde 1995 hasta la crisis financiera, y positivo desde entonces hasta 2015-. Aunque en los años más recientes la mayoría de las economías avanzadas han disfrutado de un diferencial $r$ - $g$ negativo, no debe darse por sentado que las condiciones financieras actuales de la deuda soberana continuarán indefinidamente.

\section{Implicaciones de cara al futuro}

Los elevados niveles de deuda actuales aconsejan el diseño de una estrategia de consolidación a medio y largo plazo, que permita generar márgenes de maniobra para hacer frente a los retos futuros y a perturbaciones que seguro vendrán. En tan solo quince años hemos vivido dos perturbaciones extremas, que han sacudido los cimientos del funcionamiento de la economía y la situación de las finanzas públicas. La percepción de que estos shocks extremos pueden ser cada vez más frecuentes, en un entorno de globalización de las relaciones comerciales y financieras y de fenómenos extremos asociados al cambio climático o a crisis sanitarias como la actual, justifica por sí sola la necesidad de tener márgenes de maniobra a nivel nacional, complementados con una coordinación internacional creciente al menos dentro de las instituciones europeas. También, se debe generar espacio fiscal para abordar las necesidades de inversión asociadas a los retos de la digitalización, el cambio climático y afrontar presiones de gasto asociadas al envejecimiento de la población.

Además, pese a que los factores que justifican la caída de los tipos de interés sean de naturaleza estructural, la evidencia reciente resumida en el apartado anterior hace que no se puedan descartar cambios en las condiciones de financiación de los Gobiernos que hagan que el diferencial entre tipos de interés y crecimiento sea menos favorable. La incertidumbre reciente sobre la persistencia 
TABLA 1

EPISODIOS DE REDUCCIÓN DE LA DEUDA, 1985-2021

\begin{tabular}{|c|c|c|c|c|c|c|c|c|c|c|c|c|c|}
\hline & \multirow[b]{2}{*}{ Periodo } & \multirow[b]{2}{*}{$\begin{array}{l}\text { Deuda } \\
\text { inicial }\end{array}$} & \multirow[b]{2}{*}{$\begin{array}{l}\text { Deuda } \\
\text { final }\end{array}$} & \multirow[b]{2}{*}{$\begin{array}{c}\text { Variación } \\
\text { acmda. de la } \\
\text { deuda pública }\end{array}$} & \multirow[b]{2}{*}{ Duración } & \multicolumn{4}{|c|}{$\begin{array}{l}\text { Determinantes de la reducción } \\
\text { de deuda }\end{array}$} & \multicolumn{4}{|c|}{$\begin{array}{l}\text { Otras variables de interés } \\
\quad \text { (prom. periodo) }\end{array}$} \\
\hline & & & & & & $\begin{array}{l}\text { Crecimiento } \\
\text { nominal }\end{array}$ & Interés & $\begin{array}{l}\text { Saldo } \\
\text { primario }\end{array}$ & $\begin{array}{c}\text { Ajuste } \\
\text { flujo-fondo }\end{array}$ & $\begin{array}{l}\text { Crecimiento } \\
\text { real }\end{array}$ & Inflación & $\begin{array}{l}\text { Saldo } \\
\text { primario } \\
\text { ajustado } \\
\text { de ciclo }\end{array}$ & $\begin{array}{l}\text { Tipo de } \\
\text { interés }\end{array}$ \\
\hline Suecia & $1985-1990$ & 59,7 & 39,3 & 20,4 & 6 & - & - & - & - & 2,4 & 4,4 & 6,1 & 6,1 \\
\hline Bélgica & 1993-2007 & 135,2 & 87,3 & 47,9 & 14 & $-53,2$ & 72,2 & $-62,6$ & $-4,2$ & 2,5 & 1,5 & 4,7 & 5,6 \\
\hline Irlanda & 1993-2006 & 90,1 & 23,6 & 66,5 & 13 & $-59,6$ & 22,8 & $-46,0$ & 16,4 & 7,4 & 4,2 & 2,8 & 4,9 \\
\hline España & $1996-2007$ & 65,4 & 35,8 & 29,7 & 11 & $-40,8$ & 29,9 & $-24,5$ & 5,8 & 3,8 & 3,2 & 0,8 & 5,3 \\
\hline Italia & $1994-2004$ & 119,7 & 105,1 & 14,6 & 10 & $-40,2$ & 61,8 & $-31,5$ & $-4,8$ & 1,7 & 3,0 & 3,4 & 6,7 \\
\hline Holanda & 1993-2007 & 75,4 & 43,0 & 32,4 & 14 & $-29,1$ & 27,1 & $-26,0$ & $-4,4$ & 3,0 & 2,2 & 1,8 & 5,6 \\
\hline Finlandia & 1994-2008 & 56,2 & 32,6 & 23,6 & 14 & $-19,4$ & 15,1 & $-39,7$ & 20,4 & 3,8 & 2,1 & 4,1 & 5,7 \\
\hline Suecia & $1995-2008$ & 68,7 & 37,5 & 31,2 & 14 & - & - & - & - & 3,1 & 1,4 & 3,2 & 5,3 \\
\hline Reino Unido & 1995-2001 & 44,5 & 34,1 & 10,4 & 6 & - & - & - & - & 3,5 & 6,6 & 1,6 & 6,9 \\
\hline EE UU & 1993-2001 & 70,4 & 53,2 & 17,3 & 8 & - & - & - & - & 3,6 & 6,3 & - & - \\
\hline Alemania & $2012-2019$ & 81,1 & 59,6 & 21,5 & 7 & $-18,3$ & 11,0 & $-19,1$ & 4,9 & 1,5 & 1,8 & 2,1 & 1,8 \\
\hline Irlanda & 2013-2019 & 119,9 & 57,4 & 62,6 & 7 & $-59,4$ & 18,0 & $-5,9$ & $-15,2$ & 8,6 & 2,1 & 0,2 & 3,1 \\
\hline Holanda & $2014-2019$ & 67,9 & 48,7 & 19,1 & 5 & $-12,3$ & 6,7 & $-6,9$ & $-6,6$ & 1,8 & 1,4 & 1,2 & 1,9 \\
\hline Austria & 2012-2019 & 81,9 & 70,5 & 11,4 & 7 & $-19,7$ & 16,9 & $-7,2$ & $-1,4$ & 1,4 & 1,8 & 1,0 & 2,6 \\
\hline Portugal & 2016-2019 & 131,5 & 117,2 & 14,3 & 4 & $-21,6$ & 14,2 & $-9,2$ & 2,3 & 1,8 & 1,7 & 1,2 & 3,3 \\
\hline
\end{tabular}

del repunte de la inflación y de las restricciones de oferta que han surgido en la salida de la crisis sanitaria se está traduciendo en un aumento de los tipos de interés a largo plazo. Por tanto, será necesario diseñar un plan de consolidación, para implementar en cuanto se supere la crisis económica y social provocada por la COVID-19.

\section{Elementos clave a la hora de diseñar una estrategia de consolidación a medio plazo}

El desafío es extraordinario como muestra que los episodios de consolidación hayan sido poco frecuentes en la historia económica reciente (Eichengreen et al., 2021).

En la Tabla 1 se presentan los episodios de consolidación que han culminado con éxito entre las economías avanzadas desde 1985. Se considera exitoso aquel episodio de consolidación en el que se consigue una reducción permanente de la deuda de al menos 10 pp del PIB. Como se puede comprobar, los mayores episodios de consolidación en la historia económica reciente -como los abordados por Irlanda y Bélgica entre 1993 y mediados de los 2000 y por Irlanda en el periodo 2013-2019_ combinaron un elevado crecimiento económico con una notable mejora del saldo primario, de manera que ambos factores contribuyeron a la reducción de la deuda, compensando sobradamente el pago por intereses, particularmente alto en el caso de Bélgica.

En general, los procesos de consolidación presupuestaria que tuvieron lugar en los países europeos inmediatamente antes de la introducción del euro fueron 
mucho más ambiciosos que los que se observaron posteriormente, alentados por el necesario cumplimiento de los criterios de convergencia que los países tenían que cumplir para formar parte de los países fundadores de la UEM. Y todos ellos combinaron casi por igual el crecimiento económico y la consolidación fiscal, mientras que los ajustes flujo-fondo asociados a operaciones financieras han tenido, en general, una incidencia reducida en la contención de la deuda. En ese sentido, la literatura empírica confirma que el crecimiento económico es un ingrediente esencial de todo proceso de consolidación fiscal y que un ajuste fiscal demasiado agresivo, como los implementados en el periodo inmediatamente posterior a la crisis financiera, puede tener efectos adversos sobre los niveles de deuda si reduce el crecimiento económico a través de los multiplicadores (Abbas et al., 2019; Nickel et al., 2010).

En el caso de España existe un precedente de consolidación fiscal exitosa durante el proceso de acceso a la UEM, cuando se consiguió reducir la deuda en casi 30 pp del PIB, si bien, en comparación con otros países, este episodio descansó en mayor medida en el crecimiento económico que en el ajuste presupuestario.

Existe un cierto consenso en la literatura sobre el hecho de que las consolidaciones fiscales deben iniciarse cuando el PIB ha vuelto a una senda de crecimiento robusta y su duración debe establecerse teniendo en cuenta la magnitud del ajuste global a llevar a cabo de modo que, en principio, a mayor ajuste mayor duración. No obstante, hay circunstancias que pueden recomendar acelerar el ritmo de consolidación $-\mathrm{y}$, por tanto, acortar la duración del episodio - como la posibilidad de fatiga fiscal, el riesgo de aumento de los costes de financiación de la deuda soberana o de pérdida de acceso a los mercados.

Además, cuando la consolidación a acometer es de magnitud elevada, la literatura señala que se deben contemplar medidas tanto por el lado del gasto como por el lado de los ingresos, preservando el gasto más productivo, revisando bonificaciones o exenciones fiscales y explorando nuevos tributos no distorsionantes. Las políticas de evaluación del gasto público resultan esenciales, especialmente en periodos de consolidación fiscal.

Además, las estrategias de consolidación tienen más probabilidad de éxito si se acompañan de otras medidas de política económica que apuntalen el crecimiento y, en particular, de políticas por el lado de la oferta que refuercen la productividad, la competitividad exterior y aumenten el PIB de medio plazo. En este contexto, el PRTR constituye una oportunidad histórica para lograr estos objetivos. Por último, la literatura señala que las instituciones y las normas fiscales pueden, cuando son sólidas, reforzar la credibilidad de los esfuerzos de consolidación contribuyendo al éxito del ajuste. A ello se dedica el siguiente subapartado.

\section{Repensar el marco fiscal de la UE}

Dentro del debate sobre la reforma de las reglas fiscales en la UE —que precede al estallido de la pandemia y cuya necesidad se acrecienta en este contexto según muchos autores (Martin et al., 2021) - se ha planteado la conveniencia de mantener las reglas actuales y, más en concreto, las sendas de ajuste basadas en el saldo estructural, así como las referencias clásicas de Maastricht del $3 \%$ del PIB aplicable al déficit público y del $60 \%$ del PIB aplicable a la deuda pública.

Por un lado, el límite del $60 \%$ se encuentra extraordinariamente alejado de la situación actual de la mayoría de EE MM. Lo mismo puede decirse respecto a los niveles de saldo estructural en muchos de los países de la UE. Las reglas europeas establecen el paso al brazo correctivo del Pacto de Estabilidad y Crecimiento (PEC) para aquellos países en los que, por un lado, el nivel de deuda exceda el umbral del $60 \% \mathrm{y}$, por otro, la diferencia con ese objetivo se reduzca a un ritmo inferior de una vigésima parte al año ${ }^{11}$. No obstante, la aplicación de esta

\footnotetext{
${ }^{11}$ Fuera del periodo transitorio para la aplicación de la regla de deuda -durante el cual, los requisitos de ajuste anual se derivaban de la regla de deuda a través del denominado minimum linear structural adjustment (MLSA) - , los requisitos de ajuste anual se establecen en función de
} 
regla de deuda se ha suspendido en la práctica, ya que la Comisión ha venido considerando que el cumplimiento de los requisitos del brazo preventivo opera como circunstancia atenuante en la elaboración del informe previsto en el artículo 126(3) del Tratado de Funcionamiento de la Unión Europea (TFEU) ${ }^{12}$. A esta escasa operatividad práctica se une la discusión sobre la supuesta «optimalidad» de ese umbral ${ }^{13}$, es decir, se cuestiona que el $60 \%$ sea en sí mismo un nivel que garantice la sostenibilidad de las finanzas públicas — para todos los países y en todos los periodos- especialmente en un momento en el que los costes de financiación se sitúan en niveles bajos. Esto equivale a cuestionar la validez de esta referencia como ancla a partir de la cual poder derivar una senda de ajuste adecuada para la política fiscal.

En lo que concierne a las sendas de ajuste estructural, la volatilidad de las estimaciones de output gap - variable clave para determinar el saldo estructural— implica que el análisis sobre si los objetivos fiscales se cumplen o no es también altamente volátil, lo que dificulta la aplicación del marco fiscal.

\section{Implicaciones fiscales para España del cumplimiento del objetivo de deuda del PEC}

En la consecución del objetivo de deuda del $60 \%$ intervienen distintos elementos, de modo que para poder fijar objetivos operacionales acordes con esa senda de reducción de deuda es necesario hacer proyecciones y supuestos sobre las variables determinantes de la dinámica de la deuda, analizando la sensibilidad de cada

la matriz de requerimientos del brazo preventivo. El cumplimiento de la regla de deuda, junto con el criterio del $3 \%$, se aplica para clasificar a los Estados miembros entre aquellos que deben estar en el brazo preventivo y el correctivo y no para determinar los requisitos de ajuste anual.

12 Véase, por ejemplo, European Commission (2017).

${ }^{13}$ En el periodo anterior a la entrada en la UEM, se calculó que el diferencial entre los tipos de interés y el crecimiento se situaba en promedio en el entorno de 2 pp. En consecuencia, con una inflación del $2 \%$, la estabilización a medio plazo de los niveles de deuda vigentes, en el entorno del $60 \%$, resultaba coherente con el mantenimiento de un déficit público total en el entorno del $3 \%$ del PIB. La referencia del $60 \%$ se corresponde con el promedio de los niveles de deuda de los países de la UEM en ese momento. factor en la evolución teniendo en cuenta que algunos de ellos, como el crecimiento y los tipos de financiación de las emisiones de deuda, no están bajo el control de las autoridades fiscales.

En un horizonte de medio plazo, las proyecciones para la deuda dependen de la posición macroeconómica y fiscal de partida de la economía y de la posición cíclica que se supone que se va cerrando de manera gradual en un periodo de 5 años. En el largo plazo, la economía crece según su potencial, las expectativas de precios están ancladas en las de la política monetaria, y el saldo público dependerá de un componente primario estructural que, en ausencia de medidas, se supondrá constante, más la carga de intereses dependiente del stock de deuda y los tipos a los que está emitida.

Por tanto, generar una dinámica de reducción de deuda requiere derivar una senda de ajuste del déficit primario hasta alcanzar un saldo objetivo que permita alcanzar esa dinámica descendente. La senda de ajuste necesaria, junto con el saldo primario objetivo, vendrá marcada tanto por el ancla de deuda como por el año de consecución de la misma (60 \%, en el caso que nos ocupa, y para tomar referencias en el entorno de las dos décadas, se toman los años 2040 y 2045).

La consecución del objetivo de deuda se puede lograr a través de distintas sendas de ajuste, en un proceso de consolidación muy intenso en pocos años o a través de un proceso más gradual, que se alargará en el tiempo y requerirá alcanzar un superávit más elevado. Tal como se puede apreciar en la Figura 4, una ratio de deuda del $60 \%$ en 2040 demandaría una consolidación fiscal cuya magnitud de ajuste anual oscilaría entre los 0,55 y 1,05 pp y cuya duración oscilaría entre los catorce y los cinco años hasta alcanzar un superávit primario entre el 5 y el 2,75\%, respectivamente. Las sendas comprendidas entre estos dos rangos originarían un descenso de 60 puntos en la ratio de deuda, de las cuales un tercio será consecuencia de la acumulación de saldos fiscales superavitarios, y las otras dos terceras partes, consecuencia del efecto bola de nieve, esto es, de mantener un crecimiento por encima de los tipos de interés implícitos de la deuda. 
FIGURA 4

\section{SENDAS DE AJUSTE DEL SALDO PRIMARIO COMPATIBLES CON UNA RATIO DEL $60 \%$ EN 2040}

(En \% PIB)
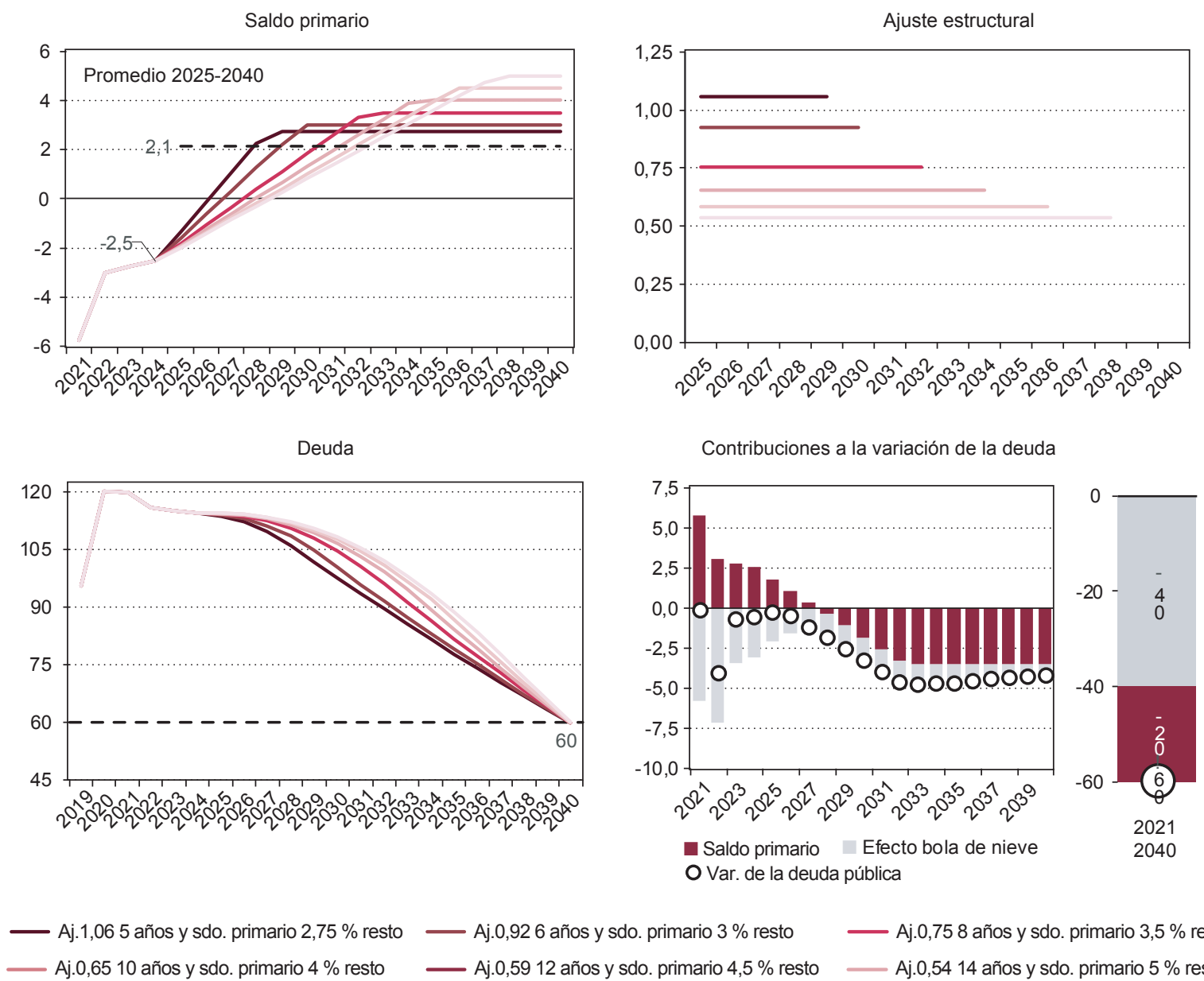

- Aj.0,75 8 años y sdo. primario $3,5 \%$ resto Aj.0,65 10 años y sdo. primario 4 \% resto Aj.0,59 12 años y sdo. primario $4,5 \%$ resto

FUENTE: Elaboración propia.

Cualquiera de estas sendas implica un saldo primario medio del entorno del 2,1\% en el periodo 2025-2040, esto es, un saldo aproximadamente en cuatro puntos superior al registrado en las dos primeras décadas del siglo $(-1,8 \%)$. Más allá del mantenimiento de un superávit primario elevado en términos históricos, la dificultad del ejercicio de consolidación radicaría en el ajuste estructural requerido hasta alcanzarlo, tanto por la intensidad como por la duración de este, intensidad que se vería acentuada al considerar el incremento del gasto estructural relativo al incremento del gasto en pensiones (que añadiría un ajuste adicional de 1,4 puntos en media en el periodo).

La combinación de un saldo primario del 2,1 \% con un crecimiento nominal medio del $3,1 \%$ está muy por encima de la relación histórica observada para estas 


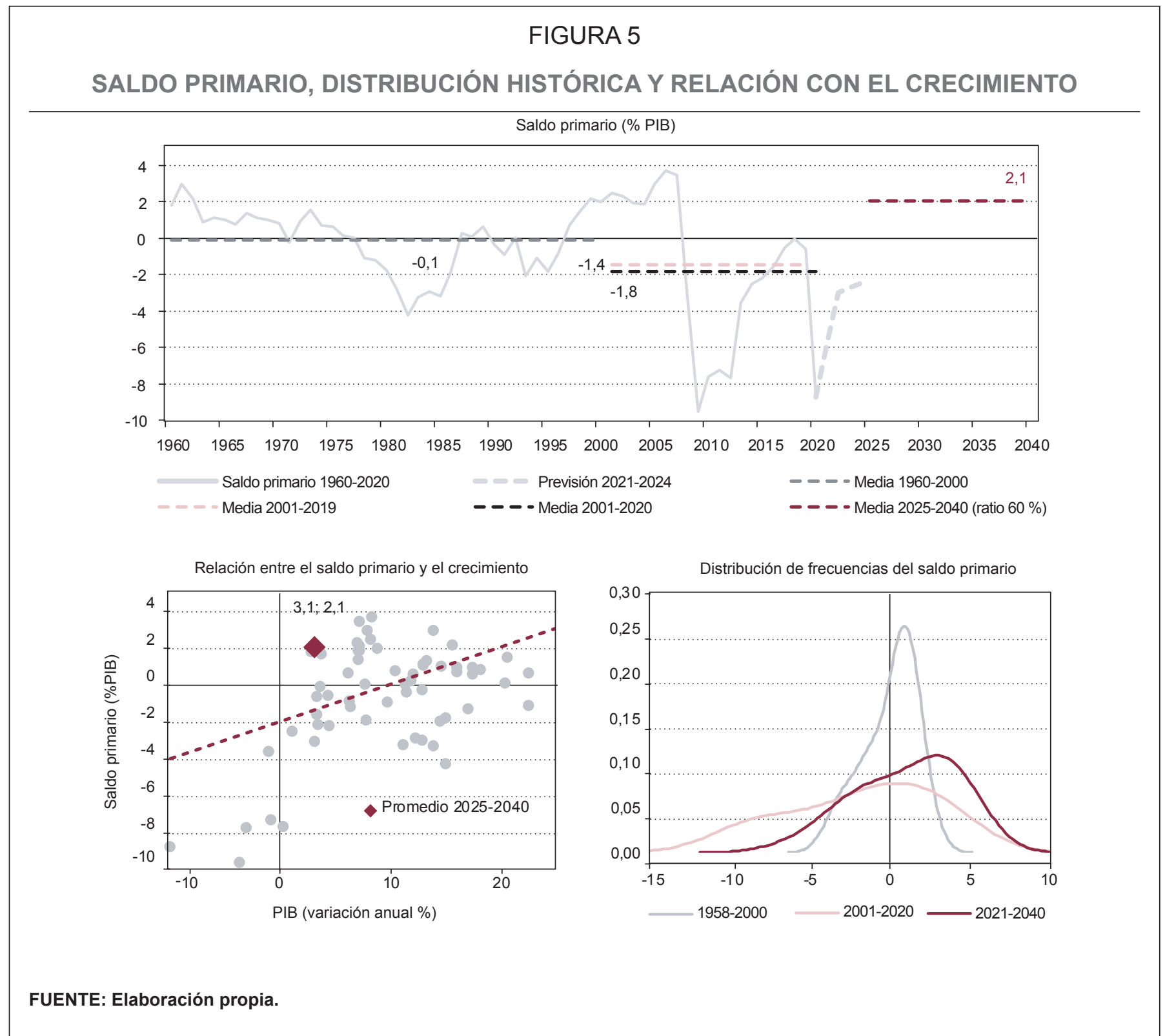

variables en los últimos 60 años. Igualmente, el cumplimiento del objetivo de deuda del PEC implicaría registrar una concentración de saldos primarios mucho más elevados que los registrados en las últimas décadas, tal como se puede comprobar en la comparativa de su distribución de frecuencias históricas (Figura 5). Otros países como Italia o Grecia se enfrentarían a una situación todavía más exigente.
Mantener unas reglas diseñadas para un entorno económico pasado y que no se corresponde con el actual puede deteriorar de manera severa su credibilidad, eliminando su posible tracción política. Existe el riesgo de que se perciban como desfasadas para la opinión pública y, en última instancia, deslegitimadas.

En este sentido, varias son las voces que plantean que deben diferenciarse sendas y objetivos de deuda 


\section{FIGURA 6}

\section{DISTRIBUCIÓN DE FRECUENCIAS DEL SALDO PRIMARIO REQUERIDO SEGÚN DISTINTAS ANCLAS DE DEUDA Y PLAZOS PARA SU CONSECUCIÓN}

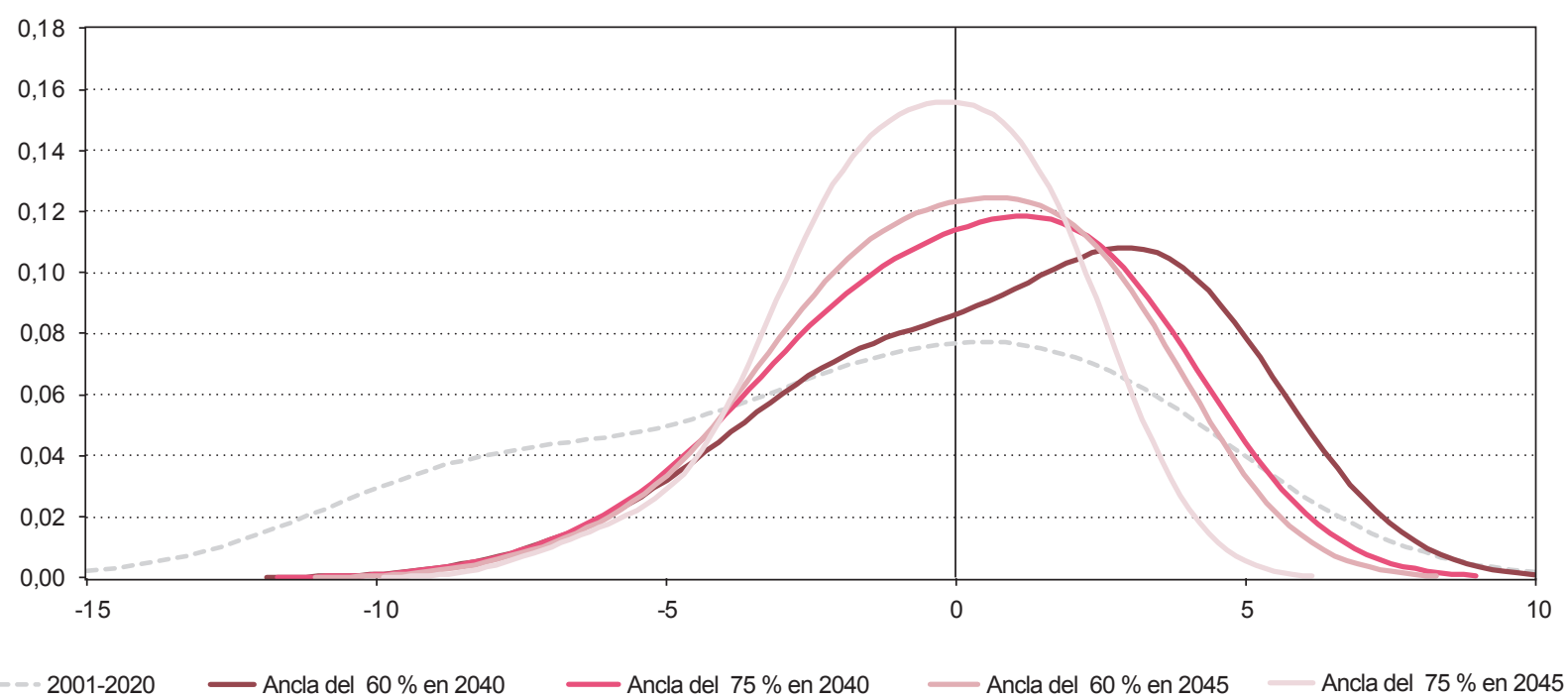

FUENTE: Elaboración propia.

específicos por países (European Fiscal Board, 2020) sustituyendo, de este modo, a las reglas actuales, únicas e iguales para todos los países. La literatura que se presenta en el subapartado anterior sustentaría esta diferenciación al señalar que la sostenibilidad de la deuda depende no solo del contexto macroeconómico, sino también de las características estructurales de cada país.

La ventaja de los enfoques que adoptan referencias específicas para cada país es que permiten tener en cuenta elementos que son clave a la hora de valorar la sostenibilidad de las finanzas públicas y que van más allá del nivel puntual de deuda. Esto debe tenerse en cuenta tanto en la determinación del objetivo final a medio plazo como en el ritmo adecuado de progresión hacia ese objetivo.

Alternativas más factibles y razonables desde el punto de vista económico pasan por reducir el ajuste requerido sin variar el plazo, esto es, resituar el ancla en un valor superior, o aumentar el periodo de ajuste, tal como muestra la Figura 6.

Esta diferenciación por países debe ir acompañada de un distinto equilibrio institucional entre el nivel comunitario y el nivel nacional. Es decir, un nuevo reparto de las tareas de orientación y supervisión de la política fiscal entre las distintas instituciones que dote de un mayor protagonismo a las instituciones fiscales independientes a nivel nacional, potenciando su conocimiento específico de las circunstancias nacionales (European Union Independent Fiscal Institutions, 2021).

Más allá del debate sobre la determinación del objetivo a medio plazo, existe un amplio consenso sobre la necesidad de simplificar las recomendaciones fiscales. La mayoría de las propuestas apuestan por operacionalizar el objetivo de deuda a medio plazo mediante una regla de gasto, que pasaría a ser la única referencia para la evaluación del cumplimiento 
de las normas fiscales. Esta simplificación supondría al menos dos ventajas respecto al marco actual: por un lado, la regla de gasto trae consigo una mayor transparencia frente a métricas volátiles y no observables, como el déficit cíclicamente ajustado; además, se trata de una referencia más próxima a las variables presupuestarias sobre las que finalmente se adoptan las decisiones políticas en el marco de elaboración de los presupuestos generales del Estado. De este modo, la conexión entre el objetivo macrofiscal y su instrumentalización presupuestaria es más inmediata y transparente.

Por último, la crisis ha subrayado una vez más la necesidad de una mayor profundización de la UEM. Un elemento crucial en este sentido sería la creación de una capacidad fiscal central permanente, financiada con auténticos recursos propios, de tamaño significativo y cuyo gasto apoyara las prioridades de inversión de la UE. Debería, además, tener capacidad de endeudamiento en caso de grandes shocks, respaldando así una verdadera capacidad fiscal contracíclica en la UEM.

\section{Conclusiones}

La literatura empírica no es concluyente acerca de la relación existente entre los niveles de deuda y el crecimiento económico ni sobre los niveles de deuda prudentes que un país puede sostener sin desencadenar reacciones adversas en los mercados. Aun así, existen argumentos de peso para reconducir los niveles de deuda hacia valores que reduzcan la vulnerabilidad ante cambios en las condiciones de financiación y que permitan recuperar los márgenes fiscales para hacer frente a perturbaciones tan severas como las acaecidas en los últimos años. A ello se añade la incertidumbre sobre el modelo de crecimiento que prevalecerá tras la crisis, ya que la persistencia de los niveles de inflación que se observan en la actualidad podría llevar asociado un tensionamiento de las condiciones de financiación de los soberanos.
Los desafíos que conlleva la reducción de la deuda son extraordinarios, especialmente si se tiene en cuenta el aumento del gasto asociado a la transición demográfica, que presionará los niveles de deuda en un futuro. El deterioro de las expectativas de crecimiento a largo plazo y la persistencia de bajas tasas de inflación plantean desafíos significativos para alcanzar niveles de deuda que en el pasado consideramos seguros, a pesar de los bajos niveles de tasas de interés asociados a estos desarrollos. Un conjunto de reformas orientadas a mejorar el crecimiento potencial y aprovechar la capacidad tractora que ofrece el PRTR es clave y deberá venir acompañado de una estrategia de consolidación a medio plazo gradual, sostenida y realista, que preserve el crecimiento económico.

Estas reflexiones cobran relevancia de cara a la revisión del marco de supervisión fiscal europeo. Existe consenso en torno a las propuestas que abogan por situar la sostenibilidad de la deuda a medio y largo plazo en el centro del marco fiscal, dejando a un lado el enfoque cortoplacista que ha guiado la supervisión fiscal europea durante las últimas décadas. Un marco que proporcione señales más claras y transparentes sobre la senda de medio plazo necesaria para reconducir los desequilibrios fiscales hacia posiciones más saneadas. No obstante, las referencias de deuda que se establecieron en el momento de creación de la UEM pueden no ser válidas en el contexto macroeconómico actual. Además, los elevados niveles de deuda con los que salimos de la crisis sanitaria hacen que la regla de deuda —que implica una reducción anual de una vigésima parte de la distancia que separa los niveles registrados de deuda de la referencia del $60 \%$ del PIB - no sea aplicable. Por ello, será necesario revisar cómo establecer objetivos de deuda razonables, que deberían ser diferenciados por países, y otorgar mayor capacidad a las instituciones fiscales independientes para supervisar la programación a medio plazo garantizando el cumplimiento de esos objetivos. 


\section{Referencias bibliográficas}

Abbas, S. A., Pienkowski, A. \& Rogoff, K. (Eds.). (2019). Sovereign Debt: A Guide for Economists and Practitioners. Oxford University Press.

Alloza, M., Andrés, J., Pérez, J. J. \& Rojas, J. A. (2020). Implicit public debt thresholds: An operational proposal. Journal of Policy Modeling, 42(6), 1408-1424.

Baum, A., Checherita-Westphal, C. D. \& Rother, P. (2013). Debt and growth: New evidence for the euro area. Journal of International Money and Finance, 32(C), 809-821.

Blanchard, O. (2019). Public Debt and Low Interest Rates. American Economic Review, 109(4), 1197-1229.

Blanchard, O. \& Summers, L. H. (Eds.). (2019). Evolution or Revolution? Rethinking Macroeconomic Policy after the Great Recession. MIT Press.

Blanchard, O. \& Ubide, Á. (2019, July 15). Why Critics of a More Relaxed Attitude on Public Debt Are Wrong. PIIE, Peterson Institute for International Economics. Real Time Economic Issues Watch. https://www.piie.com/ blogs/realtime-economic-issues-watch/why-critics-morerelaxed-attitude-public-debt-are-wrong

Burriel, P., Checherita-Westphal, C. D., Jacquinot, P., Schonlau, M. \& Stahler, N. (2020). Economic consequences of high public debt: evidence from three large scale DSGE models. ECB, European Central Bank, Working Paper Series No. 2450.

Caner, M., Grennes, T. \& Koehler-Gleib, F. (2010). Finding the tipping point--when sovereign debt turns bad. World Bank Policy Research, Working Paper No. 5391. https://ssrn. com/abstract $=1651432$

Cecchetti, S. G., Mohanty, M. S. \& Zampolli, F. (2011). The Real Effects of Debt. BIS, Bank for International Settlements, Working Paper No. 352. https://ssrn.com/ abstract $=1946170$

Checherita-Westphal, C. D. \& Domingues, J. (2020). Interest rate-growth differentials on government debt: an empirical investigation for the euro area. ECB, European Central Bank, Working Paper No. 2486.

Checherita-Westphal, C. D. \& Rother, P. (2012). The impact of high government debt on economic growth and its channels: An empirical investigation for the euro area. European economic review, 56(7), 13921405. https://econpapers.repec.org/article/eeeeecrev/ v_3a56_3ay_3a2012_3ai_3a7_3ap_3a1392-1405.htm

Christiano, L., Eichenbaum, M. \& Rebelo, S. (2011). When Is the Government Spending Multiplier Large? Journal of Political Economy, 119(1), 78-121.

De Grauwe, P. (2012). The governance of a fragile Eurozone. Australian Economic Review, 45(3), 255-268.
DeLong, J. B. \& Summers, L. H. (2012). Fiscal policy in a depressed economy. Brookings Papers on Economic Activity, 43(1), 233-297.

Douglas, J. W. \& Raudla, R. (2020). Who is Afraid of the Big Bad Debt? A Modern Money Theory Perspective on Federal Deficits and Debt. Public Budgeting \& Finance, 40(3), 6-25.

Égert, B. (2015). Public debt, economic growth, and nonlinear effects: Myth or reality? Journal of Macroeconomics, 43(C), 226-238. https://econpapers.repec.org/article/eeejmacro/ v_3a43_3ay_3a2015_3ai_3ac_3ap_3a226-238.htm

Eichengreen, B., El-Ganainy, A., Esteves, R. \& Mitchener, K. J. (2021). In Defense of Public Debt. Oxford University Press.

Esteve, V. \& Tamarit, C. (2018). Public debt and economic growth in Spain, 1851-2013. Cliometrica, 12(2), 219-249. https://doi. org/10.1007/s11698-017-0159-8

European Commission. (2017). Italy. Report prepared in accordance with Article 126(3) of the Treaty. COM(2017) 106 final. https://ec.europa.eu/info/sites/default/files/ com2017_106_en_act_part1_v6.pdf

European Commission. (2021). The 2021 Ageing Report: Economic and Budgetary Projections for the EU Member States (2019-2070). https://ec.europa.eu/info/ publications/2021-ageing-report-economic-and-budgetaryprojections-eu-member-states-2019-2070_en

European Fiscal Board. (2020). 2020 Annual Report of the European Fiscal Board.

European Union Independent Fiscal Institutions. (2021). The role of the Independent Fiscal Institutions in assessing the sustainability of high public debt in the post-Covid era. In E. Casey \& E. Gordo (Coords.), The European Fiscal Board Annual Conference. https://ec.europa.eu/info/sites/info/files/ eddie_casey_paper_-_network_of_eu_ifis_-_the_role of_ifis_in_assessing_sustainability_of_high_public_debt_ post-covid.pdf

Fatás, A. \& Mihov, I. (2012). Fiscal policy as a stabilization tool. The B.E. Journal of Macroeconomics, 12(3), 1-68. https://econpapers.repec.org/article/bpjbejmac/ v_3a12_3ay_3a2012_3ai_3a3_3ap_3a1-68_3an_3a14.htm

Furman, J. (2016). The New View of Fiscal Policy and its Application. Vox EU, November 2.

Ghosh, A. R., Kim, J. I., Mendoza, E. G., Ostry, J. D. \& Qureshi, M. S. (2013). Fiscal fatigue, fiscal space and debt sustainability in advanced economies. The Economic Journal, 123(566), F4-F30.

Hoshi, T. \& Ito, T. (2014). Defying gravity: can Japanese sovereign debt continue to increase without a crisis? Economic Policy, 29(77), 5-44.

Kumar, M. S. \& Woo, J. (2010). Public Debt and Growth. IMF, International Monetary Fund, Working Paper No. 10/174. 
Lian, W., Presbitero, A. F. \& Wiriadinata, U. (2020). Public Debt and $\mathrm{r}-\mathrm{g}$ at Risk. IMF, International Monetary Fund, Working Paper No. 20/137.

Martin, P., Pisani-Ferry, J. \& Ragot, X. (2021). Reforming the European Fiscal Framework. Les notes du conseil analyse économique, 63.

Mauro, P. \& Zhou, J. (2020). r-g<0: Can we sleep more soundly? IMF, International Monetary Fund, Working Paper No. 20/ 52.

Mehrotra, N. R. \& Sergeyev, D. (2021). Debt Sustainability in a Low Interest Rate World. Journal of Monetary Economics, 124, S1-S18. https://doi.org/10.1016/j. jmoneco.2021.09.001

Nickel, C., Rother, P. \& Zimmermann, L. (2010). Major Public Debt Reductions: Lessons from the Past, Lessons for the Future. ECB, European Central Bank, Working Paper Series No. 1241.
Panizza, U. \& Presbitero, A. F. (2013). Public debt and economic growth in advanced economies: A survey. Swiss Journal of Economics and Statistics, 149(2), 175-204. https://doi.org/10.1007/BF03399388

Rachel, L. \& Summers, L. H. (2019). On Falling Neutral Real Rates, Fiscal Policy, and the Risk of Secular Stagnation. Brookings Papers on Economic Activity.

Reinhart, C. M. \& Rogoff, K. S. (2010). Growth in a Time of Debt. American Economic Review, 100(2), 573-578.

Romer, C. (2021). The Fiscal Policy Response to the Pandemic. Brookings Papers on Economic Activity. https://www.brookings.edu/wp-content/uploads/2021/03/ BPEASP21_Romer_conf-draft_updated.pdf

Véron, N. (2012). Europe's single supervisory mechanism and the long journey towards banking union. Bruegel Policy Contribution No. 2012/16.

Wyplosz, C. (2019). Olivier in Wonderland. VoxEU, June 17. 